\title{
Iniciativa de Ley de Desarrollo Agrario. Diez puntos contra la propiedad social
}

\author{
María del Carmen Ventura Patiño \\ El Colegio de Michoacán \\ ventura@colmich.edu.mx \\ DOI: I0.2490I/rehs.v40i157.66I
}

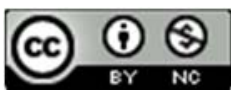

Iniciativa de Ley de Desarrollo Agrario. Diez puntos contra la propiedad social por María del Carmen Ventura Patiño se distribuye bajo una Licencia Creative Commons AtribuciónNoComercial 4.0 Internacional

Fecha de recepción: i4 de enero de 2019

Fecha de aprobación: io de julio de 2019

Presentación

El 23 de octubre de 2or8, el senador Ricardo Monreal, coordinador del partido de Morena en el Senado de la República, presentó al Congreso de la Unión la Iniciativa de Ley de Desarrollo Agrario (ILDA), con la cual propone derogar la Ley Agraria publicada en I9g2. Sus objetivos no son dar marcha atrás a la política agraria neoliberal puesta en práctica en nuestro país desde hace más de tres décadas, sino mantener y ampliar las condiciones jurídicas tendientes a desarticular la propiedad social de ejidos y comunidades.

Revisemos algunos puntos. No devuelve la protección legal de las tierras de propiedad social, esto es, el carácter de imprescriptibles, inembargables e inalienables; que fue eliminada desde la contrarreforma agraria de 1992. Por el contrario, mantiene y amplia las acciones jurídicas que fomentan una concepción y ejercicio individual de los derechos agrarios por parte de sus titulares, terminando por completo con la concepción de patrimonio familiar y debilitando las instancias de decisión colectiva. Salvaguarda los tratos agrarios que han ido desgranando las tierras ejidales y comunales, principalmente a través de la enajenación de los derechos; el arrendamiento; la adquisición de dominio pleno; y la aportación de tierras a sociedades mercantiles. Ratifica que los dos primeros no requieren la autorización de la asamblea, mientras que los otros deben someterse a estos espacios de decisión, sin embargo, propone reducir los requisitos del quórum legal para las asambleas denominadas calificadas, en las que se toman decisiones de gran trascendencia para la vida colectiva de la propiedad social. Así también armoniza su contenido con las reformas estructurales, incluyendo como facultad de las 
asambleas la autorización del uso y ocupación superficial de sus tierras para las industrias de hidrocarburos y de energía eléctrica. Estas reformas privilegian el aprovechamiento y explotación de los recursos naturales considerados como estratégicos, colocándolos por encima de los derechos de los sujetos agrarios y sus modos de vida. En particular, el derecho al territorio de los pueblos y comunidades indígenas simplemente no es reconocido, en contravención con lo dispuesto por el marco jurídico internacional y el artículo primero de nuestra constitución. Por tanto, esta iniciativa atenta contra la propiedad social y pone en riesgo la permanencia de millones de familias rurales en sus hábitat.

Panorama agrario, a 26 de años de la contrarreforma agraria neoliberal

Nuestro país cuenta con una extensión de $196,437,500$ ha, de las cuales corresponden a la propiedad social 99, 714, $95^{2}$ ha, lo cual representa 50.7 \% del territorio nacional. De acuerdo con información oficial del Registro Agrario Nacional (RAN) de 20I7, la propiedad social se conforma de 32, I2I núcleos agrarios: 29,728 son ejidos y 2,393 son comunidades agrarias (cuadro I). Han sido delimitados y certificados 30,4II núcleos agrarios, que comprenden 28,439 ejidos y I,972 comunidades agrarias, cuya superficie asciende a 92, 423, 748 de ha, propiedad de 5,I66,243 de sujetos agrarios. Los I,7IO núcleos agrarios pendientes de certificar los constituyen: I,289 ejidos y 42I comunidades agrarias, con una superficie de 7, 29I, 204 de ha (cuadro 2). ${ }^{ \pm}$

Cuadro r. Datos nacionales

\begin{tabular}{|l|l|}
\hline Superficie nacional & $196,437,500$ ha \\
\hline Superficie de la propiedad social & $99,714,952$ ha \\
\hline Representación & $50.7 \%$ \\
\hline Núcleos agrarios & 32, I2I \\
\hline Ejidos & 29,728 \\
\hline Comunidades & 2,393 \\
\hline
\end{tabular}

Fuente: RAN. http://www.ran.gob.mx/ran/inf_intnal/RAN_Info_interes_nal-2oI7.pdf

Cuadro 2. Datos de certificación

\begin{tabular}{|l|l|}
\hline Núcleos agrarios certificados & $3 \mathrm{O}, 4 \mathrm{II}$ \\
\hline Ejidos & 28,439 \\
\hline
\end{tabular}

Relaciones Estudios de Historia y Sociedad, vol. XL, núm 157, 2019 


\begin{tabular}{|l|l|}
\hline Comunidades & $\mathrm{I}, 972$ \\
\hline superficie & $92,473,748$ ha \\
\hline Beneficiados & $5, \mathrm{I} 66,243$ \\
\hline Núcleos agrarios no certificados & $\mathrm{I}, 7 \mathrm{IO}$ \\
\hline Ejidos & $\mathrm{I}, 289$ \\
\hline Comunidades & $42 \mathrm{I}$ \\
\hline superficie & $7,29 \mathrm{I}, 2 \mathrm{O} 4$ ha \\
\hline
\end{tabular}

Fuente: RAN. http://www.ran.gob.mx/ran/inf_intnal/RAN_Info_interes_nal-2or7.pdf

La superficie ejidal registrada a nivel nacional asciende a 82, 408, 563 ha, 2 que pertenecen a 2,964,656 ejidatarios. ${ }^{3}$ Los estados con mayor número de ejidos son: Veracruz $(3,669)$, Chiapas (3,I47) y Michoacán (I,762). Las entidades que concentran mayor superficie ejidal son: Chihuahua (9, 369, 962 ha), Coahuila $(6,164$, or 8 ha) y Durango $(5,807,536$ ha).. Por su parte, la superficie comunal registrada en el país corresponde a I7, 292, I66 ha, ${ }^{5}$ en manos de 842,258 comuneros. - El mayor número de comunidades agrarias se encuentran en Oaxaca (738), Guerrero (I97) y Estado de México (I79). Los estados con mayor superficie comunal son: Oaxaca $(5,837,709$ ha), Durango $(2,535,788$ ha) y Guerrero (I, 7I 8,479 ha) (cuadro 3$) .7$

Cuadro 3. Núcleos agrarios y superficie registrada

\begin{tabular}{|l|l|}
\hline Núcleos agrarios & Superficie y sujetos agrarios \\
\hline Ejidos & $82,408,563 \mathrm{ha}$ \\
\hline Ejidatarios & $2,964,656$ \\
\hline Comunidades & $\mathrm{I} 7,292, \mathrm{I} 66 \mathrm{ha}$ \\
\hline Comuneros & 842,258 \\
\hline
\end{tabular}

Fuente: RAN. http://www.ran.gob.mx/ran/indic_bps/2_SER-20I7.pdf http://www.ran.gob.mx/ran/indic_bps/I7_SCR-20I7.pdf

Relaciones Estudios de Historia y Sociedad, vol. XL, núm 157, 2019 


\section{http://datos.ran.gob.mx/conjuntoDatosPublico.php}

Los tratos agrarios tienen como propósito propiciar un mercado de tierras y atraer la inversión. La enajenación o cesión de los derechos agrarios, la adquisición del dominio pleno y la constitución de sociedades civiles y mercantiles modifican derechos de propiedad, mientras que la renta, aparcería y préstamo implican el usufructo de la tierra. Todos ellos constituyen el menú de posibilidades jurídicas que han ido debilitando a la propiedad social. Revisemos algunas cifras: sobre la adquisición de dominio pleno, consistente en cambiar de régimen de propiedad ejidal a propiedad privada, el RAN indica que hasta 20I7: se han realizado en la quinta parte del total de ejidos certificados, es decir, 284,94I parcelas se han separado del régimen ejidal, las cuales comprenden 3, 516, 625 ha. Lo anterior, representa II.5\% de las 30, 382, 3ir ha de la superficie total parcelada que ha sido certificada. Los estados con mayor superficie que ha adquirido dominio pleno son: Baja California (853, 99i ha), Coahuila $(544,565$ ha) y Sonora (372, Io8 ha) (cuadro 4$).$

Cuadro 4. Dominio pleno

\begin{tabular}{|c|c|c|c|c|}
\hline $\begin{array}{c}\text { Ejidos } \\
\text { certificados }\end{array}$ & $\begin{array}{c}\text { Total de superficie } \\
\text { parcelada certificada } \\
\text { (ha) }\end{array}$ & $\begin{array}{c}\text { Ejidos con } \\
\text { dominio pleno }\end{array}$ & $\begin{array}{c}\text { Número de parcelas } \\
\text { con dominio pleno }\end{array}$ & $\begin{array}{c}\text { Superficie con } \\
\text { dominio pleno (ha) }\end{array}$ \\
\hline $28,43 \mathrm{I}^{*}$ & $30,382,3 \mathrm{II}$ & 5,875 & $284,94 \mathrm{I}$ & $3,5 \mathrm{I} 6,625$ \\
\hline Representación & & $20.6 \%$ & & II.5\% \\
\hline
\end{tabular}

*Hay una diferencia de 8 núcleos agrarios con respecto a los datos proporcionados por el propio RAN sobre los datos de certificación. Quizá se deba a la temporalidad de los datos.

Fuente:

RAN. http://www.ran.gob.mx/ran/ind_dp/Ejidos_ParcelasCertificadas_conDominioPleno_2OI 7.pdf

Sobre la enajenación o cesión de derechos agrarios, desafortunadamente el RAN no proporciona información del avance histórico, únicamente aparecen los datos de enero a agosto de 20I8. Sólo en este periodo la enajenación comprende una superficie de 788, 585, 569 ha. Las entidades federativas con mayor número de superficie enajenada son Sinaloa (I82, 407 ha), Coahuila (I27, 803 ha) y Yucatán $\left(96,984\right.$ ha). ${ }^{2}$

De acuerdo con los resultados del IX Censo Ejidal de 2007, Héctor Robles señala que:

La compraventa de tierras se ha generalizado; en dos de cada tres núcleos agrarios [...] Si bien predominan las transacciones entre miembros de los ejidos y comunidades, una proporción importante $(33 \%)$ se realiza con personas ajenas, lo

Relaciones Estudios de Historia y Sociedad, vol. XL, núm I57, 2019 
que contraviene lo señalado en el Artículo 8o de la Ley Agraria. Se está haciendo sin cumplir los procedimientos normativos [...] las transacciones de tierras han involucrado, apenas el $2.9 \%$ de los ro5 millones de hectáreas que pertenecen a ejidos y comunidades; la circulación de la tierra no ha conducido a su acaparamiento o concentración ni superar el minifundio ni a mejorar las condiciones de producción [...], no han frenado las transacciones irregulares de la tierra [...] En el año 2000 se inscribieron 35,803 actos de enajenación, mientras que, para 2008 se incrementaron a 62,055, lo que significó un crecimiento del 73.3\% en este tipo de actos (Robles 20io, I3, 22).

Respecto al arrendamiento tampoco hay cifras oficiales del RAN, debido a que es un trato agrario que no requiere inscripción ante esta institución. Además de que el arrendamiento, en la mayoría de los casos, es un trato de palabra que se celebra entre las partes, por lo que, difícilmente habrá un registro confiable. Héctor Robles proporciona algunos datos: "De acuerdo con el VIII Censo Agrícola Ganadero 2007, se encuentran rentadas 2 millones 667 mil hectáreas" (Robles 20I0, 25). Tampoco existe información precisa sobre quiénes son los arrendatarios, pero podemos señalar que entre ellos se encuentran otros ejidatarios, ya sea con parcelas colindantes o con quienes tienen alguna relación de parentesco, pero también aquellos que han ido concentrando superficies considerables dentro del núcleo ejidal, acaparando y controlando los recursos tierra y agua, quienes aprovechan los créditos o apoyos destinados al campo y además establecen relaciones cercanas con distintos tipos de funcionarios relacionados con los asuntos agrarios y con los procesos productivos, también suelen tener una influencia importante en los cargos de representación ejidal. Asimismo, existen agroempresas que rentan superficies importantes, imponen el precio de la renta y las condiciones del contrato, sustituyendo los cultivos tradicionales por otros más rentables, modificando la organización socioespacial y convirtiendo a los ejidatarios o comuneros en jornaleros de sus propias tierras, promueven sistemas de cultivo intensivos, extrayendo grandes cantidades de agua y degradando las tierras, además de la contaminación que dejan a su paso por el uso de agroquímicos.

Pero existe otra modalidad de despojo, la denominada agricultura por contrato:

Básicamente el productor pone la tierra, el riego, la maquinaria, la energía eléctrica, los combustibles (gasolina, diésel), el mantenimiento del equipo (bombas, tractores, implementos), los fletes y la mano de obra requerida por la totalidad de las labores agrícolas, la empresa proporciona al productor la plántula y los agroquímicos (fertilizantes y pesticidas), aunque los costos son descontados al productor en su balance final de cuentas [...] El suministro de estos elementos por parte de las industrias, así como la asesoría técnica, que invariablemente se entrega al productor, constituyen el medio a través del cual se trata de asegurar la calidad de los productos [...] la empresa fija qué, cómo y dónde se cultiva limitando al ejidatario o productor contratado (Steffen y Echánove 2003, 36-37). Cuando ya no es conveniente para la empresa seguir produciendo en determinados ejidos o parcelas, va en busca de nuevos lugares que les permita asegurar la cantidad y calidad del producto (García $\underline{2018,96)}$.

Relaciones Estudios de Historia y Sociedad, vol. XL, núm 157, 2019 
Este mecanismo implica menos riesgos para los empresarios, debido a que tienen el control del proceso productivo a través de sus técnicos, sin realizar ninguna inversión, puesto que venden a los ejidatarios todo el paquete tecnológico, determinan los cultivos y los precios, además de condicionar su compra a los estándares de calidad definidos por el mercado.

De este modo, el paquete de posibilidades jurídicas es diverso. Si bien no se ha dado el regreso a los latifundios como se vaticinaba (Calva 20I2), a través de grandes propiedades, existe una selección de tratos agrarios dependiendo de los intereses del capital. Por ejemplo, los fraccionadores han ido adquiriendo parcelas conurbadas a bajos precios, que en su momento adquirieron dominio pleno, para el desarrollo de proyectos de vivienda con los que obtienen grandes ganancias. De igual modo, el sector turístico se ha beneficiado de esta modalidad, en ejidos y comunidades con este potencial. El arrendamiento y la compra de parcelas es una opción para aquellos sujetos agrarios que van acaparando tierras y agua al interior de los ejidos, que por lo regular tienen el control político de estos núcleos. El arrendamiento también resulta atractivo para algunas agroempresas que, como ya comentamos, extraen los nutrientes de la tierra, aprovechan las fuentes de agua y pagan precios ínfimos por las parcelas. Estas empresas se ubican en las mejores regiones agrícolas, que ofrecen óptimas condiciones para sus cultivos y la infraestructura necesaria para la exportación, como lo vemos también por parte de las empresas que prefieren la agricultura por contrato.

La propia ILDA señala que en los núcleos agrarios existen: 6o \% de la porción terrestre de las áreas naturales protegidas de orden federal, con una gran riqueza en biodiversidad; $80 \%$ de los bosques y selvas; dos terceras partes de los recursos hídricos y 6,500 de los II,360 kilómetros de litoral nacional (ILDA 20I8,4). Sobre minería, podemos comentar que, de los 25 mil I78 títulos de concesiones, "entre los años 2000-20I2 se concesionaron en los territorios indígenas alrededor de 2, I73, I4I hectáreas [...] de las 28 millones de hectáreas identificadas" (Boege 20I3. 3). Como podemos apreciar, lo que está en juego con este nuevo marco legal es la riqueza natural, los ecosistemas y la biodiversidad, así como formas de vida y culturas concretas. A continuación, presentamos algunos de los puntos que consideramos sustanciales de la ILDA.

\section{Iniciativa de Ley de Desarrollo Agrario. Diez puntos contra la propiedad social}

I. Fin del derecho agrario como patrimonio familiar. Lo reduce al derecho del tanto del cónyuge y los hijos a ejercer en la enajenación de la parcela y en la primera enajenación del dominio pleno, como ya lo señalaba la Ley Agraria en vigor. La ILDA propone que las tierras parceladas y de Tierras de Uso Común (TUC) formarán parte de la sociedad conyugal si así lo determinan las partes. Además, privilegia la individualización del derecho, el titular puede heredar ya sea en calidad de cotitularidad o bien designar a un sucesor por cada certificado parcelario y de uso común. Lo cual implica que el derecho agrario deja de ser indivisible.

2. Enajenación y arrendamiento. La ILDA propone que también los posesionarios, sujetos agrarios reconocidos en la Ley Agraria de 1992, cuyos derechos estaban restringidos, ahora puedan enajenar y arrendar sus parcelas, así como a adquirirlas. De este modo, la superficie de los derechos agrarios de los 720,307 posesionarios ${ }^{\underline{10}}$ que existen en el país también entrará al 
mercado de tierras. También agrega que, para efectos de la enajenación, se hará un avalúo de los derechos parcelarios y en su caso de agua, por parte de una institución bancaria o del Instituto de Administración y Avalúos de Bienes Nacionales (INDABIN).

3. Crea las condiciones jurídicas para que las asambleas aprueben: a) contratos y convenios que tengan por objeto el uso o disfrute por parte de terceros de las tierras de uso común, previa manifestación de impacto ambiental. Tratándose de obras o proyectos que, conforme a las legislaciones especializadas, requieran evaluación de impacto ambiental, se hará del conocimiento de la asamblea; b) otorgar el usufructo de las tierras de uso común, como garantía para la obtención de créditos, a fin de financiar proyectos que se realicen en estas tierras; c) cambiar el destino de tierras de uso común a tierras parceladas o para el asentamiento humano, previo dictamen por parte de la Secretaría de Medio Ambiente y Recursos Naturales; d) autorizar a los ejidatarios y a los posesionarios para que adopten el dominio pleno sobre sus parcelas y la aportación de las tierras de uso común a una sociedad, en los términos de esta Ley; e) aprobar la terminación del régimen ejidal cuando previo dictamen de la Procuraduría Agraria solicitado por el núcleo de población se determine que ya no existen las condiciones para su permanencia; f) instaurar, modificar y cancelar el régimen de explotación colectiva; $\stackrel{\square}{\mathrm{g}}$ ) autorizar el uso y ocupación superficial de tierras ejidales para las actividades estratégicas de las industrias de hidrocarburos y energía eléctrica, de conformidad con las leyes de la materia.

Además, modifica el quórum legal requerido para las asambleas calificadas, en primera convocatoria, de tres cuartas partes del total de ejidatarios que se estipula en la actual Ley Agraria, ahora será suficiente con la asistencia únicamente de dos terceras partes. Asimismo, establece que no se contabilizarán las abstenciones para determinar la mayoría de las votaciones.

4. Dominio pleno. Para el caso de la primera enajenación de las parcelas con dominio pleno, La ILDA mantiene el derecho del tanto de la familia, pero excluye de este derecho a las personas que hayan trabajado por más de un año, a los ejidatarios, los avecindados y al núcleo de población ejidal, como lo señala la legislación vigente. Lo cual representa que personas extrañas al ejido puedan adquirir tales parcelas sin mayor impedimento. Asimismo, se elimina la obligación del Comisariado Ejidal y Consejo de Vigilancia de verificar que se cumpla con el procedimiento indicado por la legislación. Para esta acción jurídica se requiere la aprobación de una asamblea calificada, que como ya comentamos ha flexibilizado sus requerimientos de asistencia para declarar su validez. Ha incorporado para esta acción a los posesionarios y a las colonias agrícolas y ganaderas, que también podrán convertir sus tierras a propiedad privada.

5. Tierras de Uso Común (TUC). Se puede cambiar su destino a tierras parceladas o Asentamiento Humano, por tanto, serán susceptibles de enajenar, adquirir dominio pleno y arrendar, entre otros. El usufructo de las TUC se puede otorgar como garantía para la obtención de créditos. En el país existen $19,565^{12}$ ejidos registrados con tierras destinadas al uso común, con una superficie de 50, 676, 293 ha, ${ }^{13}$ lo cual representa 6I.4 \% del total de la superficie ejidal registrada, sobre la que se está facilitando su circulación en el mercado. 
6. Sociedades civiles y mercantiles. Retoma al pie de la letra lo señalado por la Ley Agraria vigente. Para la aportación de tierras a estas figuras jurídicas se requiere de una asamblea calificada, que acabamos de señalar se ha simplificado. Esta decisión es de suma importancia, en virtud de que las tierras pasan a ser propiedad de dichas sociedades, se convierten en acciones llamadas tipo T, en caso de liquidación de la sociedad, el derecho que tienen quienes hayan aportado sus tierras, sea un ejidatario en lo particular o el núcleo agrario, sólo tendrán derecho de preferencia, respecto a los demás socios, para recibir tierra en pago o bien de adquirirlas, una vez que se liquiden las deudas, esto en caso de que cuenten con el capital para hacerlo.

7. Tierras de las comunidades que pertenecen a pueblos indígenas. La ILDA señala que las comunidades pueden tener el régimen ejidal o comunal conforme sus Resoluciones Presidenciales o sentencias de los Tribunales Unitarios Agrarios (TUA). Les reconoce el derecho a elegir a sus autoridades o representantes, conforme sus sistemas normativos internos, "garantizando la participación de las mujeres en condiciones de equidad frente a varones, en un marco de respeto al pacto federal y la soberanía de los estados". Las instituciones de los tres órdenes de gobierno "podrán reconocer a sus representantes electos".

Para aquellas comunidades que no cuentan con su carpeta básica, establece que éstas podrán acudir a los tribunales agrarios a solicitar el reconocimiento de sus derechos de propiedad legítimos por parte de la autoridad jurisdiccional, a través de sus representantes electos, conforme a sus sistemas normativos internos. Al parecer, los autores de esta Iniciativa desconocen que el artículo ro7 constitucional reconoce la personalidad jurídica de las comunidades de hecho. Por lo que son los funcionarios de las instituciones gubernamentales las que deben respetar y reconocer dicha personalidad. Otro fundamento jurídico es una tesis jurisprudencial emitida por la Suprema Corte de Justicia de la Nación (SCJN), la cual sostiene:

el aceptar la tesis de una tercera categoría de comunidades, sin personalidad para comparecer ante una autoridad judicial, es regresar al estado que guardaban las comunidades en el periodo comprendido entre la consumación de la Independencia y la Constitución de i9r7 y que se agravó por la ley de 25 de junio de i856 [...] y si la norma fundamental no distingue, el intérprete tampoco puede hacer distinción. ${ }^{14}$

También la ILDA señala que aquellas comunidades pertenecientes a un pueblo indígena que hayan sido despojadas de sus tierras pueden acudir a los TUA para solicitar la restitución, para lo cual se requiere aportar pruebas que acrediten su derecho, "títulos o reconocimientos que datan generalmente de la época novohispana". Al respecto, podemos comentar que los procedimientos de restitución fueron la vía agraria menos favorecida, por las complicaciones para comprobar el despojo y acreditar la propiedad de las tierras, por ello, desde la legislación agraria de 1927 se instauró el procedimiento de conversión, para que en caso de que no procediera la primera, se siguiera el procedimiento vía dotación ejidal, por ello existen ejidos con población indígena. De modo que, si en ioo años no procedió la vía restitutoria, ahora será más difícil hacerlo, puesto que las tierras reclamadas han sido objeto ya sea de dotación ejidal o de reconocimiento y titulación de bienes comunales de comunidades vecinas o bien forman parte de pequeñas propiedades, con historiales agrarios complejos. 
8. Pueblos y comunidades indígenas. No se reconoce su derecho al territorio, contemplado en los tratados internacionales y en el artículo primero de nuestra constitución. Tampoco se reconoce el derecho a la Consulta con carácter vinculatorio.

En la ILDA, los derechos de los pueblos y comunidades indígenas se reducen al llamado "derecho de participación", consistente en dar a conocer a los ejidos y comunidades indígenas la información sobre las inversiones planteadas en sus tierras y a conocer sobre los impactos positivos y negativos de los proyectos de inversión. Esto significa que tienen derecho a conocer, pero no a decidir. Por ejemplo, contempla que en los casos en que un proyecto afecte "directamente" el modo de vida, los pueblos y comunidades indígenas tienen derecho a que "sus recomendaciones" sean incorporadas. Si el proyecto afecta de manera "significativa", como lo sería la pérdida de tierras, el agotamiento de recursos necesarios para la subsistencia física y cultural o impactos negativos a la salud, entre otros, señala que deberá obtenerse el consentimiento previo, libre e informado. Como podemos apreciar, en ningún momento se prohíbe este tipo de proyectos, no los considera como violatorios de los derechos de los pueblos y comunidades indígenas, únicamente indica que se procederá a obtener su consentimiento, aunque no dice si éste tendrá efectos vinculatorios, en caso de una respuesta negativa.

Para ser coherente con lo reconocido por los tratados internacionales, la ILDA deberá plasmar el reconocimiento del derecho al territorio, considerado como el hábitat de los pueblos y comunidades, y no restringirlo a tierra, para ello, es necesario aprobar una serie de medidas legislativas de protección jurídica, como restituir el carácter de imprescriptibles, inembargables e inalienables, a todos los núcleos agrarios sin excepciones. Prohibir todo trato agrario que tienda a su desarticulación, como los son el arrendamiento, las enajenaciones, la adquisición de dominio pleno y la aportación de las tierras a todo tipo de sociedades. Reconocer el derecho de propiedad y posesión de las tierras, y a ocupar los lugares sagrados. A obtener su consentimiento para cualquier medida que tenga que ver con sus territorios, cuyos resultados deben ser vinculatorios, entre otros derechos. Es indispensable armonizar la ley agraria con los tratados internacionales en materia de derechos indígenas, en particular, los que tienen que ver con los derechos a la tierra y al territorio.

9. Representación y justicia en núcleos agrarios con población indígena. Señala que podrán elegir a sus autoridades o representantes conforme sus propios procedimientos. En materia de justicia, agrega que se "considerarán" sus sistemas normativos "siempre y cuando" no contravengan los derechos humanos reconocidos por la constitución federal y los tratados internacionales. En los juicios, retoma las disposiciones vigentes, en caso de que una de las partes no sepa leer el idioma español, el tribunal realizará una versión sintetizada de los puntos esenciales de las actuaciones y de la sentencia dictadas por él, en la "lengua o variantes dialectales" de la que se trate. Se le asignará gratuitamente un defensor y un traductor que conozca su cultura, hable su lengua y el idioma español, para que le explique, en su lengua, el alcance y consecuencias del proceso que se le sigue, es decir, en el marco del derecho positivo. De modo que no hay ningún reconocimiento a otras fuentes del derecho. 
Io. Contratos relativos al uso y ocupación superficial de tierras ejidales o comunales para las industrias de hidrocarburos y energía eléctrica. La asamblea calificada, cuyo quórum se ha reducido, podrá autorizar el uso y ocupación superficial de las tierras del ejido o comunidad, o de sus titulares en lo individual para las actividades de las industrias señaladas. Una propuesta a modo con las reformas estructurales, que ya comentamos.

\section{Documentos}

A continuación, presentamos un cuadro comparativo entre la Ley Agraria vigente (I992) (200 artículos) y la Iniciativa de Ley de Desarrollo Agrario (ILDA) (272 artículos). Para facilitar su lectura seleccionamos únicamente los artículos que consideramos constituyen las bases jurídicas que atentan contra la propiedad social y que han sido comentados en este texto. Los hemos organizado en los siguientes apartados: I) enajenación; 2) arrendamiento; 3) dominio pleno; 4) sociedades mercantiles; 5) Pueblos y comunidades indígenas; y 6) uso y ocupación de las tierras para las industrias de hidrocarburos y energía eléctrica. Se exponen en su versión original.

Cuadro 5. Resumen comparativo entre la Ley Agraria de 1992 y la ILDA

\begin{tabular}{|c|c|}
\hline Ley Agraria I992 & Iniciativa de Ley de Desarrollo Agrario \\
\hline Enajenación & \\
\hline $\begin{array}{l}\text { Artículo 8o. Los ejidatarios podrán } \\
\text { enajenar sus derechos parcelarios a otros } \\
\text { ejidatarios o avecindados del mismo núcleo } \\
\text { de población. }\end{array}$ & $\begin{array}{l}\text { Artículo in4. Los ejidatarios y los } \\
\text { posesionarios podrán enajenar sus derechos } \\
\text { parcelarios a otros ejidatarios, posesionarios o } \\
\text { avecindados del mismo núcleo de población. }\end{array}$ \\
\hline $\begin{array}{l}\text { Para la validez de la enajenación se } \\
\text { requiere: }\end{array}$ & $\begin{array}{l}\text { Para la validez de la enajenación se } \\
\text { requiere: }\end{array}$ \\
\hline $\begin{array}{l}\text { a) La manifestación de conformidad por } \\
\text { escrito de las partes ante dos testigos, } \\
\text { ratificada ante fedatario público; } \\
\text { b) La notificación por escrito al cónyuge, } \\
\text { concubina o concubinario y los hijos del } \\
\text { enajenante, quienes, en ese orden, gozarán } \\
\text { del derecho del tanto, el cual deberán } \\
\text { ejercer dentro del término de treinta días } \\
\text { naturales contados a partir de la } \\
\text { notificación a cuyo vencimiento caducará } \\
\text { tal derecho. Será aceptable para este efecto } \\
\text { la renuncia expresada por escrito ante dos }\end{array}$ & $\begin{array}{l}\text { I. La manifestación de conformidad por } \\
\text { escrito de las partes ante dos testigos, en la } \\
\text { que contendrá el estado civil del enajenante, } \\
\text { en su caso, el número de hijos y la constancia } \\
\text { de la notificación del derecho del tanto, } \\
\text { ratificada ante Notario Público. } \\
\text { II. La notificación por escrito al cónyuge, } \\
\text { concubina o concubinario y a los hijos del } \\
\text { enajenante, quienes, en ese orden, gozarán del } \\
\text { derecho del tanto, el cual deberán ejercer } \\
\text { dentro del término de treinta días naturales } \\
\text { contados a partir de la notificación, a cuyo }\end{array}$ \\
\hline
\end{tabular}


testigos e inscrita en el Registro Agrario Nacional. En caso de que se desconozca el domicilio o ubicación de las personas que gozan del derecho del tanto, se procederá en términos de lo dispuesto por el párrafo tercero del artículo 84 de esta Ley, y

Inciso reformado DOF 19-12-2016

c) Dar aviso por escrito al comisariado ejidal.

Realizada la enajenación, el Registro Agrario Nacional, procederá a inscribirla y expedirá los nuevos certificados parcelarios, cancelando los anteriores. Por su parte, el comisariado ejidal deberá realizar la inscripción correspondiente en el libro respectivo.

Artículo reformado DOF 17-04-2008

Arrendamiento

Artículo 79. El ejidatario puede aprovechar su parcela directamente o conceder a otros ejidatarios o terceros su uso o usufructo, mediante aparcería, mediería, asociación, arrendamiento o cualquier otro acto jurídico no prohibido por la ley, sin necesidad de autorización de la asamblea o de cualquier autoridad. Asimismo, podrá aportar sus derechos de usufructo a la formación de sociedades tanto mercantiles como civiles.

\section{Dominio pleno}

Artículo 8I. Cuando la mayor parte de las parcelas de un ejido hayan sido delimitadas y asignadas a los ejidatarios en los términos del artículo 56, la asamblea, con las formalidades previstas a tal efecto por los vencimiento caducará tal derecho. Será aceptable para este efecto la renuncia expresada por escrito ante dos testigos e inscrita en el Registro Agrario Nacional. En caso de que se desconozca el domicilio o ubicación de las personas que gozan del derecho del tanto, se procederá en términos de lo dispuesto por esta Ley.

III. El avalúo referencial que al efecto expida un valuador acreditado en una institución bancaria o en el Instituto de Administración y Avalúos de Bienes Nacionales, sobre los derechos sobre la parcela y en su caso, sobre los derechos de agua inherentes a la misma.

IV. Dar aviso por escrito al comisariado ejidal y copia de la inscripción en el Registro Agrario Nacional.

Artículo ir2. El ejidatario y el posesionario pueden aprovechar su parcela directamente o conceder a otros ejidatarios o terceros su uso o usufructo, mediante aparcería, mediería, asociación, arrendamiento o cualquier otro acto jurídico no prohibido por la ley, sin necesidad de autorización de la asamblea o de cualquier autoridad. Asimismo, podrá aportar sus derechos de usufructo a la formación de sociedades tanto mercantiles como civiles. 
artículos 24 a 28 y 3i de esta ley, podrá resolver que los ejidatarios puedan a su vez adoptar el dominio pleno sobre dichas parcelas, cumpliendo lo previsto por esta ley.

Artículo 82. Una vez que la asamblea hubiere adoptado la resolución prevista en el artículo anterior, los ejidatarios interesados podrán, en el momento que lo estimen pertinente, asumir el dominio pleno sobre sus parcelas, en cuyo caso solicitarán al Registro Agrario Nacional que las tierras de que se trate sean dadas de baja de dicho Registro, el cual expedirá el título de propiedad respectivo, que será inscrito en el Registro Público de la Propiedad correspondiente a la localidad.

A partir de la cancelación de la inscripción correspondiente en el Registro Agrario Nacional, las tierras dejarán de ser ejidales y quedarán sujetas a las disposiciones del derecho común.

Artículo 83. La adopción del dominio pleno sobre las parcelas ejidales no implica cambio alguno en la naturaleza jurídica de las demás tierras ejidales, ni significa que se altere el régimen legal, estatutario o de organización del ejido.

La enajenación a terceros no ejidatarios tampoco implica que el enajenante pierda su calidad de ejidatario, a menos que no conserve derechos sobre otra parcela ejidal o sobre tierras de uso común, en cuyo caso el comisariado ejidal deberá notificar la separación del ejidatario al Registro Agrario Nacional, el cual efectuará las cancelaciones correspondientes.

Artículo 84. En caso de la primera enajenación de parcelas sobre las que se ejidatarios puedan a su vez adoptar el dominio pleno sobre dichas parcelas, cumpliendo lo previsto por esta Ley.

Artículo ir6. Una vez que la asamblea hubiere adoptado la resolución prevista en el artículo anterior, los ejidatarios interesados podrán, en el momento que lo estimen pertinente, asumir el dominio pleno sobre sus parcelas, en cuyo caso solicitarán al Registro Agrario Nacional que las tierras de que se trate sean dadas de baja de dicho Registro, el cual expedirá el título de propiedad respectivo, que será inscrito en el Registro Público de la Propiedad y en el Catastro Municipal correspondiente a la localidad.

A partir de la cancelación de la inscripción correspondiente en el Registro Agrario Nacional, las tierras dejarán de ser ejidales y quedarán sujetas a las disposiciones del derecho común.

Artículo ir7. La adopción del dominio pleno sobre las parcelas ejidales no implica cambio alguno en la naturaleza jurídica de las demás tierras ejidales, ni significa que se altere el régimen legal, estatutario o de organización del ejido.

La enajenación a terceros no ejidatarios tampoco implica que el enajenante pierda su calidad de ejidatario, a menos que no conserve derechos sobre otra parcela ejidal o sobre tierras de uso común, en cuyo caso el comisariado ejidal deberá notificar la separación del ejidatario al Registro Agrario Nacional, el cual efectuará las cancelaciones correspondientes.

Artículo ir8. En caso de la primera enajenación de parcelas sobre las que se hubiere adoptado el dominio pleno, el cónyuge, concubina o concubinario, hijos, en 
hubiere adoptado el dominio pleno, los familiares del enajenante, las personas que hayan trabajado dichas parcelas por más de un año, los ejidatarios, los avecindados y el núcleo de población ejidal, en ese orden, gozarán del derecho del tanto, el cual deberán ejercer dentro de un término de treinta días naturales contados a partir de la notificación, a cuyo vencimiento caducará tal derecho. Si no se hiciere la notificación, la venta podrá ser anulada.

El comisariado ejidal y el consejo de vigilancia serán responsables de verificar que se cumpla con esta disposición.

La notificación hecha al comisariado, con la participación de dos testigos o ante fedatario público, surtirá los efectos de notificación personal a quienes gocen del derecho del tanto. Al efecto, el comisariado bajo su responsabilidad publicará de inmediato en los lugares más visibles del ejido una relación de los bienes o derechos que se enajenan.

Artículo 85. En caso de que se presente ejercicio simultáneo del derecho del tanto con posturas iguales, el comisariado ejidal, ante la presencia de fedatario público, realizará un sorteo para determinar a quién corresponde la preferencia.

Artículo 86. La primera enajenación a personas ajenas al núcleo de población de parcelas sobre las que se hubiere adoptado el dominio pleno, será libre de impuestos o derechos federales para el enajenante y deberá hacerse cuando menos al precio de referencia que establezca la Comisión de Avalúos de Bienes Nacionales o cualquier institución de crédito

Sociedades mercantiles ese orden, gozarán del derecho del tanto, el cual deberán ejercer dentro de un término de treinta días naturales contados a partir de la notificación, a cuyo vencimiento caducará tal derecho. Si no se hiciere la notificación, la venta podrá ser anulada.

El titular del derecho parcelario será responsable de la notificación del derecho del tanto.

Artículo irg. En caso de que se presente ejercicio simultáneo del derecho del tanto con posturas iguales, el comisariado ejidal, ante la presencia de Notario Público, realizará un sorteo para determinar a quién corresponde la preferencia.

Artículo i20. La primera enajenación a personas ajenas al núcleo de población de parcelas sobre las que se hubiere adoptado el dominio pleno, será libre de impuestos o derechos federales para el enajenante y deberá hacerse cuando menos al precio de referencia que establezca el Instituto de Administración y Avalúos de Bienes Nacionales o cualquier institución de crédito.

Artículo 53. La asamblea se reunirá por lo menos una vez cada seis meses o con mayor frecuencia, cuando así lo determine su reglamento o su costumbre. Serán de la competencia exclusiva de la asamblea los siguientes asuntos:

XIX. Autorizar a los ejidatarios y posesionarios para que adopten el dominio pleno sobre sus parcelas y la aportación de las tierras de uso común a una sociedad, en los términos de esta Ley. 
Artículo 75. En los casos de manifiesta utilidad para el núcleo de población ejidal, éste podrá transmitir el dominio de tierras de uso común a sociedades mercantiles o civiles en las que participen el ejido o los ejidatarios conforme al siguiente procedimiento:

I. La aportación de las tierras deberá ser resuelta por la asamblea, con las formalidades previstas a tal efecto en los artículos 24 a 28 y 3I de esta ley;

II. El proyecto de desarrollo y de escritura social respectivos serán sometidos a la opinión de la Procuraduría Agraria, la que habrá de analizar y pronunciarse sobre la certeza de la realización de la inversión proyectada, el aprovechamiento racional y sostenido de los recursos naturales y la equidad en los términos y condiciones que se propongan. Esta opinión deberá ser emitida en un término no mayor a treinta días hábiles para ser considerada por la asamblea al adoptar la resolución correspondiente. Lo anterior, sin perjuicio de que, para los efectos de esta fracción, el ejido pueda recurrir a los servicios profesionales que considere pertinentes.

III. En la asamblea que resuelva la aportación de las tierras a la sociedad, se determinará si las acciones o partes sociales de la sociedad corresponden al núcleo de población ejidal o a los ejidatarios individualmente considerados, de acuerdo con la proporción que les corresponda según sus derechos sobre las tierras aportadas.

IV. El valor de suscripción de las acciones o partes sociales que correspondan al ejido o a los ejidatarios por la aportación de sus tierras, deberá ser cuando menos igual al
Artículo izo. En los casos de manifiesta utilidad para el núcleo de población ejidal, éste podrá transmitir el dominio de tierras de uso común a sociedades mercantiles o civiles en las que participen el ejido o los ejidatarios conforme al siguiente procedimiento:

I. La aportación de las tierras deberá ser resuelta por la asamblea, con las formalidades de mayoría calificada y formalidades especiales.

II. El proyecto de desarrollo y de escritura social respectivos serán sometidos a la opinión de la Procuraduría Agraria, la que habrá de analizar y pronunciarse sobre la certeza de la realización de la inversión proyectada, el aprovechamiento racional y sostenido de los recursos naturales y la equidad en los términos y condiciones que se propongan.

III. La Procuraduría Agraria deberá emitir la opinión en un término no mayor a treinta días hábiles, para ser considerada por la asamblea al adoptar la resolución correspondiente. Lo anterior, sin perjuicio de que, para los efectos de esta fracción, el ejido pueda recurrir a los servicios profesionales que considere pertinentes.

IV. En la asamblea que resuelva la aportación de las tierras a la sociedad, se determinará si las acciones o partes sociales de la sociedad corresponden al núcleo de población ejidal o a los ejidatarios individualmente considerados, de acuerdo con la proporción que les corresponda según sus derechos sobre las tierras aportadas.

V. El valor de suscripción de las acciones o partes sociales que correspondan al ejido o a los ejidatarios por la aportación de sus tierras, deberá ser cuando menos igual al precio de referencia que establezca el Instituto de 
precio de referencia que establezca la Comisión de Avalúos de Bienes Nacionales o cualquier institución de crédito.

V. Cuando participen socios ajenos al ejido, éste o los ejidatarios, en su caso, tendrán el derecho irrenunciable de designar un comisario que informe directamente a la asamblea del ejido, con las funciones que sobre la vigilancia de las sociedades prevé la Ley General de Sociedades Mercantiles. Si el ejido o los ejidatarios no designaren comisario, la Procuraduría Agraria, bajo su responsabilidad, deberá hacerlo.

Las sociedades que conforme a este artículo se constituyan deberán ajustarse a las disposiciones previstas en el Título Sexto de la presente ley.

En caso de liquidación de la sociedad, el núcleo de población ejidal y los ejidatarios, de acuerdo a su participación en el capital social, y bajo la estricta vigilancia de la Procuraduría Agraria, tendrán preferencia, respecto de los demás socios, para recibir tierra en pago de lo que les corresponda en el haber social.

En todo caso el ejido o los ejidatarios, según corresponda, tendrá derecho de preferencia para la adquisición de aquellas tierras que aportaron al patrimonio de la sociedad

Artículo i26. Las sociedades mercantiles o civiles no podrán tener en propiedad tierras agrícolas, ganaderas o forestales en mayor extensión que la equivalente a veinticinco veces los límites de la pequeña propiedad individual y deberán cumplir con los siguientes requisitos:
Administración y Avalúos de Bienes

Nacionales o cualquier institución de crédito.

VI. Cuando participen socios ajenos al ejido, éste o los ejidatarios, en su caso, tendrán el derecho irrenunciable de designar un comisario que informe directamente a la asamblea del ejido, con las funciones que sobre la vigilancia de las sociedades prevé la Ley General de Sociedades Mercantiles. Si el ejido o los ejidatarios no designaren comisario, la Procuraduría Agraria, bajo su responsabilidad, deberá hacerlo.

VII. Las sociedades que conforme a este artículo se constituyan con fines agrícolas, ganaderos o forestales, deberán ajustarse a las disposiciones previstas en el título correspondiente.

VIII. En caso de liquidación de la sociedad, el núcleo de población ejidal y los ejidatarios, de acuerdo a su participación en el capital social, y bajo la estricta vigilancia de la Procuraduría Agraria, tendrán preferencia, respecto de los demás socios, para recibir tierra en pago de lo que les corresponda en el haber social.

IX. En todo caso el ejido o los ejidatarios, según corresponda, tendrán derecho de preferencia para la adquisición de aquellas tierras que aportaron al patrimonio de la sociedad.

X. La aportación de tierras de uso común deberá inscribirse ante el Registro Agrario Nacional, el que expedirá el título de propiedad a favor de la sociedad a la que fue aportada la tierra y solicitará su alta en el Registro Público de la Propiedad.

Artículo i47. Las sociedades mercantiles o civiles no podrán tener en propiedad tierras 


\begin{abstract}
I. Deberán participar en la sociedad, por lo menos, tantos individuos como veces rebasen las tierras de la sociedad los límites de la pequeña propiedad individual. Al efecto, se tomará en cuenta la participación de cada individuo, ya sea directamente o a través de otra sociedad;

II. Su objeto social deberá limitarse a la producción, transformación o comercialización de productos agrícolas, ganaderos o forestales y a los demás actos accesorios necesarios para el cumplimiento de dicho objeto;
\end{abstract}

III. Su capital social deberá distinguir una serie especial de acciones o partes sociales identificada con la letra T, la que será equivalente al capital aportado en tierras agrícolas, ganaderas o forestales o al destinado a la adquisición de las mismas, de acuerdo con el valor de las tierras al momento de su aportación o adquisición.

Artículo r27. Las acciones o partes sociales de serie T no gozarán de derechos especiales sobre la tierra ni de derechos corporativos distintos a las demás acciones o partes sociales. Sin embargo, al liquidarse la sociedad sólo los titulares de dichas acciones o partes sociales tendrán derecho a recibir tierra en pago de lo que les corresponda en el haber social.

Artículo i28. Los estatutos sociales de las sociedades a que este Título se refiere deberán contener transcritas las prescripciones a que se refiere el artículo I26.

Artículo i29. Ningún individuo, ya sea directamente o a través de una sociedad, podrá detentar más acciones o partes sociales de serie $T$, ya sea de una o varias agrícolas, ganaderas o forestales en mayor extensión que la equivalente a veinticinco veces los límites de la pequeña propiedad individual y deberán cumplir con los siguientes requisitos:

I. Deberán participar en la sociedad, por lo menos, tantos individuos como veces rebasen las tierras de la sociedad los límites de la pequeña propiedad individual. Al efecto, se tomará en cuenta la participación de cada individuo, ya sea directamente o a través de otra sociedad.

II. Ningún individuo, ya sea directamente o a través de una sociedad, podrá detentar más acciones o partes sociales de serie $\mathrm{T}$, ya sea de una o varias sociedades emisoras, que las que equivalgan a la extensión de la pequeña propiedad.

III. Ninguna sociedad podrá detentar más acciones o partes sociales de serie $\mathrm{T}$, ya sea de una o varias sociedades emisoras, que las que equivalgan a una superficie igual a veinticinco veces la pequeña propiedad.

Artículo i48. Cuando una sociedad rebase los límites a la extensión de tierra permitidos por esta Ley, la Secretaría de Desarrollo Agrario, Territorial y Urbano, previa audiencia, ordenará a la sociedad que en el plazo de un año fraccione, en su caso, y enajene los excedentes o regularice su situación. Si transcurrido el plazo la sociedad no lo hubiere hecho, la dependencia seleccionará discrecionalmente las tierras que deban ser enajenadas y notificará a la autoridad estatal correspondiente para que aplique el procedimiento correspondiente.

Artículo i49. Las acciones o partes sociales de serie $\mathrm{T}$ que un individuo o sociedad tenga en exceso de las que equivalgan a la pequeña 
sociedades emisoras, que las que equivalgan a la extensión de la pequeña propiedad.

Ninguna sociedad podrá detentar más acciones o partes sociales de serie $\mathrm{T}$, ya sea de una o varias sociedades emisoras, que las que equivalgan a una superficie igual a veinticinco veces la pequeña propiedad.

Artículo izo. En las sociedades a que se refiere este título, los extranjeros no podrán tener una participación que exceda del $49 \%$ de las acciones o partes sociales de serie T.

Artículo i3r. El Registro Agrario Nacional contará con una sección especial en la que se inscribirán:

I. Las sociedades mercantiles o civiles propietarias de tierras agrícolas, ganaderas o forestales;

II. Las superficies, linderos y colindancias de los predios agrícolas, ganaderos o forestales propiedad de las sociedades a que se refiere la fracción anterior, con indicación de la clase y uso de sus tierras;

III. Los individuos tenedores de acciones o partes sociales de serie $\mathrm{T}$ de las sociedades a que se refiere la fracción I de este artículo;

IV. Las sociedades tenedoras de acciones o partes sociales de serie $T$ representativas del capital social de las sociedades a que se refiere la fracción I de este artículo;

V. Los demás actos, documentos o información que sea necesaria para vigilar el cumplimiento de lo dispuesto en este Título y que prevea el reglamento de esta ley.

Los administradores de las sociedades, así como los socios tenedores de acciones o propiedad o a veinticinco veces ésta, respectivamente, deberán ser enajenadas por su propietario o se ordenará su enajenación en los términos que para la enajenación de tierra prescribe el artículo anterior.

Artículo i67. Las sociedades mercantiles o civiles agrícolas, ganaderas o forestales, podrán constituirse con aportación de tierras sujetas a la pequeña propiedad o con aportación de tierras de uso común de origen ejidal o comunal:

I. Su objeto social deberá limitarse a la producción, transformación o comercialización de productos agrícolas, ganaderos o forestales y a los demás actos accesorios necesarios para el cumplimiento de dicho objeto;

II. Su capital social deberá distinguir una serie especial de acciones o partes sociales identificada con la letra T, la que será equivalente al capital aportado en tierras agrícolas, ganaderas o forestales o al destinado a la adquisición de las mismas, de acuerdo con el valor de las tierras al momento de su aportación o adquisición.

Artículo i68. Las acciones o partes sociales de serie T no gozarán de derechos especiales sobre la tierra ni de derechos corporativos distintos a las demás acciones o partes sociales. Sin embargo, al liquidarse la sociedad sólo los titulares de dichas acciones o partes sociales tendrán derecho a recibir tierra en pago de lo que les corresponda en el haber social.

Artículo i7o. En las sociedades a que se refiere este título, los extranjeros no podrán tener una participación que exceda del 49\% de las acciones o partes sociales de serie $\mathrm{T}$. 
partes sociales de serie $\mathrm{T}$, según corresponda, serán responsables de proporcionar al Registro la información a que se refiere este artículo, en la forma y términos que señale el reglamento respectivo de esta ley.

Artículo i32. Cuando una sociedad rebase los límites a la extensión de tierra permitidos por esta ley, la Secretaría de la Reforma Agraria, previa audiencia, ordenará a la sociedad que en el plazo de un año fraccione, en su caso, y enajene los excedentes o regularice su situación. Si transcurrido el plazo la sociedad no lo hubiere hecho, la dependencia seleccionará discrecionalmente las tierras que deban ser enajenadas y notificará a la autoridad estatal correspondiente para que aplique el procedimiento a que se refiere el artículo I24.

Artículo 133. Las acciones o partes sociales de serie $\mathrm{T}$ que un individuo o sociedad tenga en exceso de las que equivalgan a la pequeña propiedad o a veinticinco veces ésta, respectivamente, deberán ser enajenadas por su propietario o se ordenará su enajenación en los términos que para la enajenación de tierra prescribe el artículo anterior.

Serán nulos los actos o contratos por los que se pretenda simular la tenencia de acciones de serie $\mathrm{T}$.
Artículo i7i. El Registro Agrario Nacional contará con una sección especial en la que se inscribirán:

I. Las sociedades mercantiles o civiles propietarias de tierras agrícolas, ganaderas o forestales.

II. Las superficies, linderos y colindancias de los predios agrícolas, ganaderos o forestales, propiedad de las sociedades a que se refiere la fracción anterior, con indicación de la clase y uso de sus tierras.

III. Los individuos tenedores de acciones o partes sociales de serie $\mathrm{T}$ de las sociedades a que se refiere la fracción I de este artículo.

IV. Las sociedades tenedoras de acciones o partes sociales de serie T representativas del capital social de las sociedades a que se refiere la fracción I de este artículo.

V. Los demás actos, documentos o información que sea necesaria para vigilar el cumplimiento de lo dispuesto en este Título y que prevea el reglamento de esta Ley.

Los administradores de las sociedades, así como los socios tenedores de acciones o partes sociales de serie $\mathrm{T}$, según corresponda, serán responsables de proporcionar al Registro la información a que se refiere este artículo, en la forma y términos que señale el reglamento respectivo de esta Ley.

Serán nulos los actos o contratos por los que se pretenda simular la tenencia de acciones de serie $\mathrm{T}$.

Título primero 
Del ámbito de aplicación de la ley

Artículo r. La presente ley es reglamentaria del artículo 27 constitucional en materia agraria y de observancia general en toda la República.

Tiene por objeto regular los derechos de propiedad de ejidos, comunidades y sus integrantes y los procedimientos para ejercerlos en el ámbito administrativo y jurisdiccional. Asimismo, la protección de las tierras de comunidades pertenecientes a pueblos indígenas y los límites de la pequeña propiedad individual.

Capítulo sexto

Tierras de las comunidades que pertenecen a pueblos indígenas

Artículo 33. Las comunidades integrantes de un pueblo indígena, asentadas en un territorio, de acuerdo con el ejercicio de sus derechos, pueden tener el régimen ejidal o comunal conforme a las resoluciones presidenciales o sentencias de los tribunales agrarios, y elegir a las autoridades o representantes para el ejercicio de sus derechos, conforme sus sistemas normativos internos, de acuerdo con sus normas, procedimientos y prácticas tradicionales, garantizando la participación de las mujeres en condiciones de equidad frente a los varones, en un marco de respeto al pacto federal y la soberanía de los estados.

Artículo 34. Las instituciones de los tres órdenes de gobierno, los órganos constitucionalmente autónomos y los tres poderes de la Unión, para la gestión administrativa de ejidos y comunidades que se auto adscriben como indígenas, podrán reconocer a sus representantes electos, 


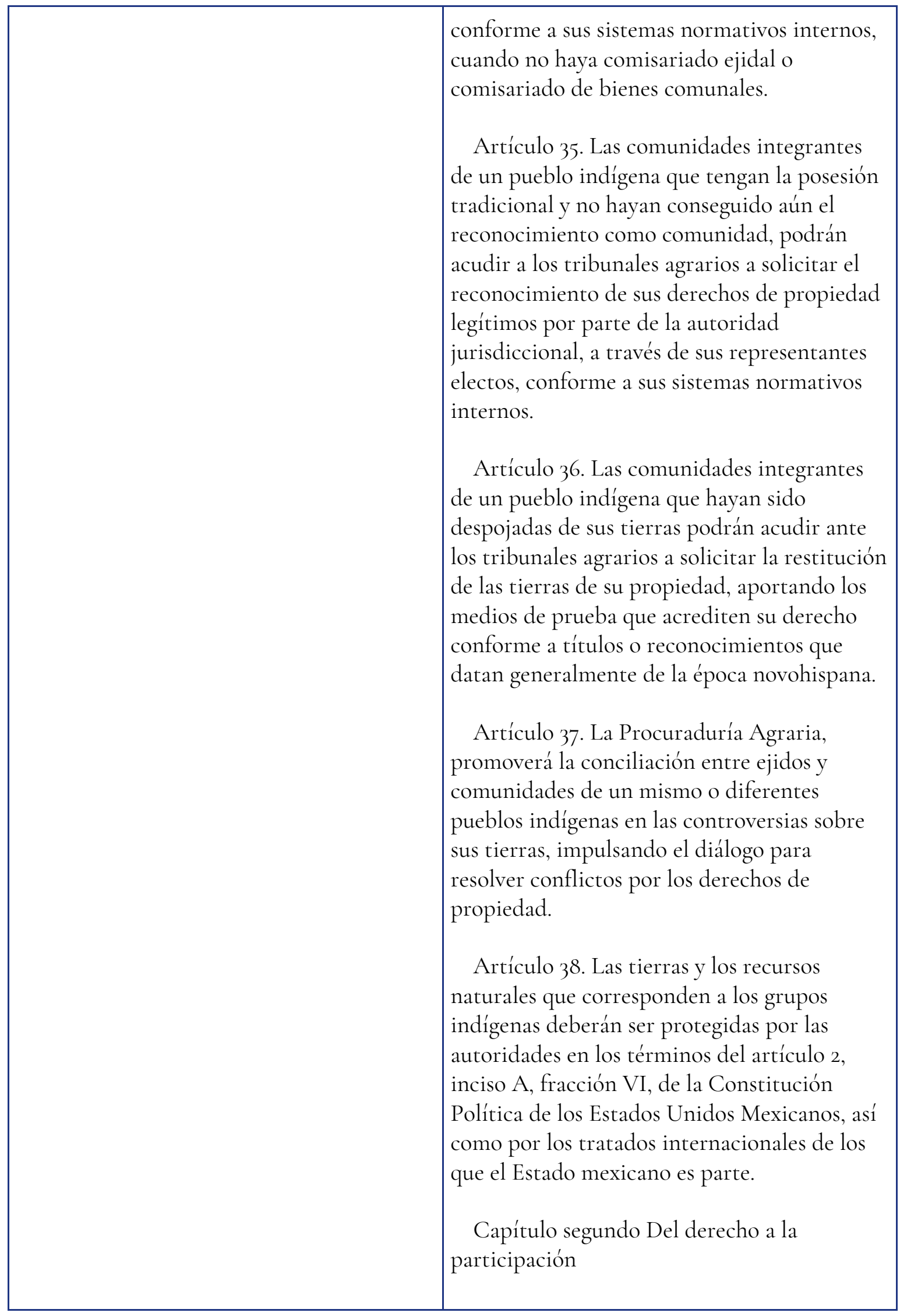

Relaciones Estudios de Historia y Sociedad, vol. XL, núm I57, 2019 
Artículo i26. Los ejidos y comunidades y sus integrantes tienen el derecho a conocer la información sobre las inversiones planteadas en tierras de su propiedad. Los inversionistas públicos y privados informarán a los ejidos y comunidades de los impactos positivos y negativos derivados de la ejecución de proyectos de inversión. En el caso de impactos ambientales negativos, darán a conocer las propuestas de medidas de mitigación para su atención.

Artículo i27. Los inversionistas públicos y privados incorporarán las recomendaciones de los ejidos, comunidades y sus integrantes que las partes acuerden procedentes.

Capítulo tercero Del derecho a la consulta tratándose de ejidos y comunidades que pertenecen a un pueblo indígena

Artículo i28. Los ejidos y comunidades que pertenezcan a un pueblo indígena, cuyas tierras estén previstas para proyectos con inversión pública y privada, tienen derecho a que se les consulte sobre la instrumentación del proyecto, informando sobre los impactos sociales, económicos y ambientales, positivos y negativos.

Artículo i29. El propósito de la consulta es

Capítulo I

Disposiciones Preliminares

Artículo i63. Son juicios agrarios los que tienen por objeto sustanciar, dirimir y resolver las controversias que se susciten con motivo de la aplicación de las disposiciones contenidas en esta ley.

Artículo i64. En la resolución de las controversias que sean puestas bajo su promover la participación activa, libre, efectiva e informada, para los procesos de toma de decisiones.

La consulta deberá sujetarse a los principios de integridad; visibilidad, accesibilidad, transparencia y en su caso confidencialidad, divulgación, interpretación justa y publicidad del resultado.

El nivel de participación y determinación de los resultados estará vinculado al grado de afectación del proyecto de inversión en la vida 
conocimiento, los tribunales se sujetarán siempre al procedimiento previsto por esta ley y quedará constancia de ella por escrito, además observarán lo siguiente:

I. Los juicios en los que una o ambas partes sean indígenas se considerarán los usos y costumbres de los pueblos o comunidades indígenas a los que pertenezcan mientras no contravengan lo dispuesto por la Constitución Política de los Estados Unidos Mexicanos y esta ley;

II. Las promociones que los pueblos o comunidades indígenas, o los indígenas en lo individual hicieren en su lengua, no necesitarán acompañarse de la traducción al español. El tribunal la hará de oficio por conducto de persona autorizada para ello;

III. Los juicios en los que una o ambas partes sean indígenas y no supieran leer el idioma español, el tribunal realizará una versión sintetizada de los puntos esenciales de las actuaciones y de la sentencia dictadas por él, en la lengua o variantes dialectales de la que se trate; debiendo agregarse en los autos constancia de que se cumplió con esta obligación.

En caso de existir contradicción entre la traducción y la resolución, se estará a lo dispuesto por esta última;

IV. El tribunal asignará gratuitamente a los indígenas un defensor y un traductor que conozca su cultura, hable su lengua y el idioma español, para que se le explique, en su lengua, el alcance y consecuencias del proceso que se le sigue.

Los tribunales suplirán la deficiencia de las partes en sus planteamientos de derecho cuando se trate de núcleos de población de las personas, la tierra y los recursos naturales.

Cuando el proyecto no impacta en el modo de vida, deberá proporcionarse toda la información del proyecto al igual que a la población en general. Si el proyecto afecta directamente al modo de vida, deberá incorporarse en el proyecto de inversión sus recomendaciones. Para el caso que haya un impacto significativo en el modo de vida, considerado como: la perdida de tierras, el desalojo de sus tierras, el posible reasentamiento, el agotamiento de recursos necesarios para la subsistencia física y cultural, la destrucción o contaminación del medio ambiente, la desorganización social y comunitaria, impactos negativos a la salud, entre otros, deberá obtenerse el consentimiento previo -durante la planeación del proyecto-, libre e informado.

\section{Capítulo segundo}

Disposiciones para la participación de personas o comunidades que se auto adscriben como indígenas

Artículo 216. En los juicios agrarios en que participen personas o ejidos o comunidades que se auto adscriban a un pueblo indígena se observará lo siguiente:

I. Se considerarán los usos y costumbres de los pueblos o comunidades indígenas a los que pertenezcan mientras no contravengan lo dispuesto por la Constitución Política de los Estados Unidos Mexicanos y los derechos humanos previstos en la Constitución y los Tratados Internacionales en los que el estado mexicano es parte.

II. Las promociones que los pueblos o comunidades indígenas, o los indígenas en lo 


\begin{tabular}{|c|c|}
\hline $\begin{array}{l}\text { ejidales o comunales, así como ejidatarios y } \\
\text { comuneros. } \\
\text { Artículo reformado DOF 22-06-2011 }\end{array}$ & $\begin{array}{l}\text { individual hicieren en su lengua, no } \\
\text { necesitarán acompañarse de la traducción al } \\
\text { español. El tribunal la hará de oficio por } \\
\text { conducto de persona autorizada para ello. } \\
\text { III. Los juicios en los que una o ambas } \\
\text { partes sean indígenas y no supieran leer el } \\
\text { idioma español, el tribunal realizará una } \\
\text { versión sintetizada de los puntos esenciales de } \\
\text { las actuaciones y de la sentencia dictadas por } \\
\text { él, en la lengua o variantes dialectales de la } \\
\text { que se trate; debiendo agregarse en los autos } \\
\text { constancia de que se cumplió con esta } \\
\text { obligación. En caso de existir contradicción } \\
\text { entre la traducción y la resolución, se estará a } \\
\text { lo dispuesto por ésta última. } \\
\text { IV. El tribunal asignará gratuitamente a los } \\
\text { indígenas un defensor y un traductor que } \\
\text { conozca su cultura, hable su lengua y el } \\
\text { idioma español, para que se le explique, en su } \\
\text { lengua, el alcance y consecuencias del proceso } \\
\text { que se le sigue. Podrá apoyarse en peritos } \\
\text { adscritos a la Administración Pública Federal, } \\
\text { Estatal o Municipal, así como a la Defensoría } \\
\text { del Poder Judicial Federal. } \\
\text { De no respetarse estas disposiciones, se } \\
\text { deberá ordenar de oficio o por resolución } \\
\text { jurisdiccional la reposición del proceso a } \\
\text { partir de la violación al debido proceso. }\end{array}$ \\
\hline \multirow[t]{2}{*}{$\begin{array}{l}\text { Uso y ocupación de las tierras para las } \\
\text { industrias de Hidrocarburos y energía eléctrica }\end{array}$} & \\
\hline & $\begin{array}{l}\text { Capítulo séptimo } \\
\text { De la validación de contratos relativos al } \\
\text { uso y ocupación superficial de tierras ejidales } \\
\text { o comunales para las industrias de } \\
\text { hidrocarburos y energía eléctrica. } \\
\text { Artículo 26r. El asignatario o contratista } \\
\text { y/o el titular de los derechos ejidales o }\end{array}$ \\
\hline
\end{tabular}


comunales, deberán presentar al Tribunal

Agrario para su validación el contrato signado para el uso y ocupación de tierras ejidales o comunales, en un plazo de hasta 90 días hábiles, conforme los lineamientos emitidos por la Secretaría de Energía para el caso de la industria de Hidrocarburos y de la Secretaría de Desarrollo Agrario, Territorial y Urbano, para la industria eléctrica.

A la promoción se deberá adjuntar la escritura pública que contenga el contrato, con sus anexos, entre los que destacan:

I. Acreditación de la personalidad de las partes.

II. Acreditación del interés jurídico de las partes.

III. Síntesis del proyecto a desarrollar.

IV. Constancia de interés para celebrar el contrato de uso y ocupación superficial entregada por el asignatario o contratista al titular de los derechos agrarios.

V. Aviso de inicio de negociación a la Secretaría de Energía si se trata de industria de Hidrocarburos o a la Secretaría de Desarrollo Agrario, si se trata de industria eléctrica.

VI. Superficie requerida y el plano correspondiente conforme a las normas técnicas del Registro Agrario Nacional.

VII. Tabuladores municipales emitidos por el Instituto de Administración y Avalúos y de Bienes Nacionales, considerando el valor comercial de la tierra.

VIII. En caso de que las partes lo hayan acordado, avalúo maestro y en su caso 
específico, emitido por un valuador del Instituto de Administración y Avalúos de Bienes Nacionales de la sección específica de reforma energética, que contenga los factores que resulten aplicables previstos en el artículo IO4 de la Ley de Hidrocarburos y 77 de la Ley de la Industria Eléctrica.

IX. Documentales que acrediten el consentimiento de las partes contratantes.

$\mathrm{X}$. En caso de ser necesario para el caso concreto, las evaluaciones de impacto social e impacto ambiental y el resultado de la consulta a comunidades pertenecientes a un pueblo indígena y en su caso el consentimiento previo, libre e informado.

Artículo 262. El Tribunal Agrario recibida la promoción podrá acordar:

I. Admitir la promoción y establecer fecha para audiencia la que deberá realizarse en un plazo de hasta zo días hábiles, a la que deberán asistir el asignatario o contratista y el núcleo agrario, con sus representantes legales, con el objeto de garantizar que los titulares de los derechos ejidales o comunales, conozcan los alcances del proyecto, los posibles impactos positivos y negativos, el monto de la contraprestación por tierra y por bienes distintos a la tierra, la duración del contrato y la superficie que comprende. Invariablemente se citará a la audiencia a la Procuraduría Agraria para asesorar al núcleo agrario de que se trate.

II. Prevenir a la parte que presentó la promoción para que en el plazo de 8 días hábiles complemente la documentación presentada en su promoción inicial, con el apercibimiento que de no presentarla se dictará el archivo del expediente y se pondrán 


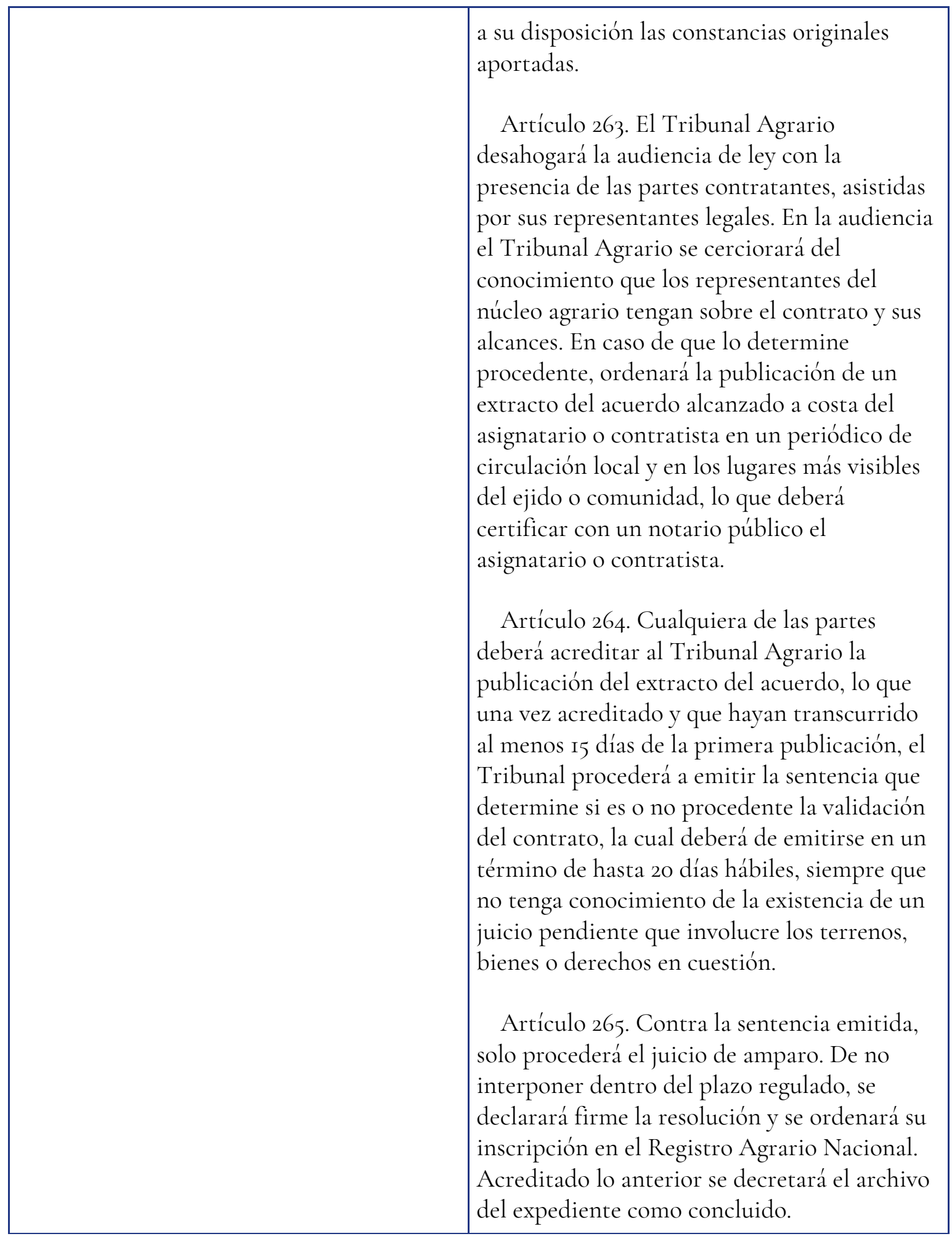




\section{Fuentes consultadas}

BOEGE, Eckart. 20I3. "El despojo de los indígenas de sus territorios en el siglo XXI", "El despojo de los indígenas de sus territorios en el siglo XXI", http://www.rebelion.org/noticia.php?id=I6gI66 (Fecha de consulta: 28 de noviembre de 20I8).

CALVA, José Luis. 20i2. "La reconstitución de los latifundios en los albores del siglo XXI". Problemas del Desarrollo. Revista Latinoamericana de Economía 23(89). http://www.revistas.unam.mx/index.php/pde/article/view/334I6 (Fecha de consulta: 28 de noviembre de 20I8)

GÓMEZ GARCÍA, José Ramón. 20i8. "El neoliberalismo en el campo mexicano: exclusión y resistencias en la reorganización socio-espacial, productiva y ambiental en dos ejidos del Bajío Guanajuatense (1982-2015)". Tesis de Doctorado en Ciencias Sociales con Especialidad en Estudios Rurales, El Colegio de Michoacán.

INICIATIVA DE LEY DE DESARROLLO AGRARIO (ILDA). 20I8. http://infosen.senado.gob.mx/sgsp/gaceta/64/I/20I8-IO-23I/assets/documentos/Inic_Morena_LDA_23IOI8.pdf (Fecha de consulta: 5 de noviembre de 20I8).

LEY AGRARIA. I992. http://www.diputados.gob.mx/LeyesBiblio/index.htm (Fecha de consulta: 15 de noviembre de 2018).

REGISTRO

AGRARIO

NACIONAL

(RAN). http://datos.ran.gob.mx/conjuntoDatosPublico.php (Fecha de consulta: 2 de noviembre de 20I8).

http://www.ran.gob.mx/ran/indic_bps/IO_SEJCUC-20I7.pdf (Fecha de consulta: 2 de marzo de 20I8).

http://www.ran.gob.mx/ran/indic_bps/I7_SCR-20I7.pdf (Fecha de consulta: 5 de noviembre de 20I8).

http://www.ran.gob.mx/ran/indic_bps/2_SER-20I7.pdf (Fecha de consulta: 7 de noviembre de 2018).

http://www.ran.gob.mx/ran/indic_bps/g_EJCUC-20I7.pdf(Fecha de consulta: 2 de marzo de 20i8).

. http://www.ran.gob.mx/ran/inf_intnal/RAN_Info_interes_nal-20I7.pdf (Fecha

de consulta: I5 de noviembre de 20i8). 
http://www.ran.gob.mx/ran/ind_dp/Ejidos_ParcelasCertificadas_conDominioPleno_20I 7.pdf (Fecha de consulta: 5 de noviembre de 2018).

ROBLES BERLANGA, Héctor. 20io. Proyecto:Dinámicas en el mercado de la tierra en América Latina. https://docplayer.es/I625II55-Proyecto-dinamicas-en-el-mercado-de-la-tierra-enamerica-latina-estudio-de-caso-mexico-investigador-responsable-hector-manuel-roblesberlanga.html (Fecha de consulta: ro de noviembre de 2018).

SUPREMA CORTE DE JUSTICIA DE LA NACIÓN (SCJN). "Jurisprudencia 238256.COMUNIDADES DE HECHO Y DE DERECHO. SCJN. Segunda Sala". Semanario Judicial de la Federación. Séptima Época. Tercera Parte. Vol. 91-96

Notas

I RAN. http://www.ran.gob.mx/ran/inf_intnal/RAN_Info_interes_nal-20I7.pdf

2 RAN. http://www.ran.gob.mx/ran/indic_bps/2_SER-20I7.pdf

$3 \underline{\text { RAN. }}$ http://datos.ran.gob.mx/conjuntoDatosPublico.php

4 RAN. http://www.ran.gob.mx/ran/indic_bps/2_SER-20I7.pdf

5 RAN. http://www.ran.gob.mx/ran/indic_bps/I7_SCR-20I7.pdf

6 RAN. http://datos.ran.gob.mx/conjuntoDatosPublico.php

7 RAN. http://www.ran.gob.mx/ran/indic_bps/I7_SCR-20I7.pdf

8 RAN.http://www.ran.gob.mx/ran/ind_dp/Ejidos_ParcelasCertificadas_conDominioPleno_20 I7.pdf

$9 \underline{\text { RAN. }}$ http://datos.ran.gob.mx/conjuntoDatosPublico.php

Io $\underline{\text { RAN. http://datos.ran.gob.mx/conjuntoDatosPublico.php }}$

II Estas dos últimas facultades están contempladas por la Ley Agraria vigente.

I2 RAN. http://www.ran.gob.mx/ran/indic_bps/q_EJCUC-20I7.pdf

I3 RAN. http://www.ran.gob.mx/ran/indic_bps/IO_SEJCUC-20I7.pdf

I4 Suprema Corte de Justicia de la Nación (SCJN). Jurisprudencia 238256.COMUNIDADES DE HECHO Y DE DERECHO. SCJN, Segunda Sala, Semanario Judicial de la Federación, séptima época, volumen 9I-96, tercera parte, Iog.

Relaciones Estudios de Historia y Sociedad, vol. XL, núm I57, 2019 